\title{
Género y despojo: el caso de Cerro de San Pedro, San Luis Potosi*
}

\author{
Gender and Dispossession: \\ The Case of the Cerro de San Pedro, San Luis Potosí
}

\author{
Ramón Cortés Cortés** \\ Colegio de Postgraduados, Campus Montecillo, México \\ Emma Zapata Martelo*** \\ Colegio de Postgraduados, Campus Montecillo, México \\ María del Rosario Ayala Carrillo**** \\ Colegio de Postgraduados, Campus Montecillo, México
}

Recibido: 04 de diciembre de 2019. Aprobado: 25 de abril de 2019 . DOI: 10.25100/lamanzanadeladiscordia.v14i1.8063

\section{Resumen}

En este trabajo se analiza, desde la perspectiva de género, el despojo territorial e identitario, a través de la ocupación del espacio físico que Minera San Xavier realizó en el municipio de Cerro de San Pedro, San Luis Potosí. Por medio de entrevistas semiestructuradas y etnografía feminista, los resultados muestran que el extractivismo minero requirió apoyarse en estructuras capitalistas y patriarcales previas y actuales que facilitaron el despojo territorial, reproduciendo $y$ ampliando un orden jerárquico de género, en donde el poder de decisión para el asentamiento de la corporación, el arrendamiento del ejido Cerro de San Pedro y el desplazamiento de la comunidad La Zapatilla, quedaron en manos de los hombres, privilegiando la experiencia masculina, mientras que la femenina experimentó un proceso de minorización e invisibilización. Para lograr despojar los territorios, capitalismo y patriarcado se aprovecharon de los cuerpos despojados de poder de las mujeres.

Palabras clave: Género y despojo; territorio; extractivismo y género; megaminería y género; minera San Xavier.

\section{Artículo de Investigación}

\section{Abstract}

In this paper, we analyze from a gender perspective the land and identity dispossession, through the occupation of the physical space by the Minera San Xavier mining company in the municipality of Cerro de San Pedro, San Luis Potosi. Through semi-structured surveys and feminist ethnography, the results show that the mining extraction had to be supported by previous and current capitalist and patriarchal structures which favored the land dispossession, thus reproducing and spreading a hierarchical gender order, where the power of decision for the settling of the corporation, the leasing of the Cerro de San Pedro ejido, and the displacement of the La Zapatilla community was all in the hands of the men, thus privileging the male experience, while the females experienced a process of minorization and invisibilization. In order to take away the land, capitalism and patriarchy take advantage of the powerless bodies of women.

Keywords: Gender and dispossession; land; extractivism and gender; megamining and gender; minera San Xavier.

* Este artículo se deriva del trabajo de tesis de maestría en el Posgrado Socioeconomía, Estadística e Informática-Desarrollo Rural del Colegio de Postgraduados, Campus Montecillo.

** Maestro en Ciencias en Estudios del Desarrollo Rural. Colegio de Postgraduados, Campus Montecillo. México. Correo electrónico: cortes. ramon@colpos.mx. ORCID: 0000-0002-7685-8201

*** Ph.D. Sociología. Universidad de Texas, Austin. Estados Unidos. Profesora-Investigadora Titular en el Colegio de Postgraduados, Campus Montecillo, México. Correo electrónico: emzapata@colpos.mx. ORCID: 0000-0002-1623-3322

**** Maestra en Ciencias en Estudios del Desarrollo Rural. Colegio de Postgraduados, Investigadora Auxiliar Titular en el Colegio de Postgraduados, Campus Montecillo, México. Correo electrónico: madel@colpos.mx. ORCID: 0000-0002-1198-6026 


\section{Introducción}

La historia de la minería en México data de tiempos de la conquista. Fue pilar de la economía en el México colonial y actualmente sigue teniendo un papel importante. Los primeros años de la colonización estuvieron marcados por el despojo y la violencia de la codicia española, durante los cuales se destruyeron las poblaciones originarias con el único fin de arrebatar el oro y la plata. En el periodo de independencia, la minería continuó siendo controlada por manos extranjeras: ingleses, franceses y estadounidenses. Esta tendencia se prolongó durante el Porfiriato, cuando el sector minero fue abierto a la inversión extranjera. En vísperas de la revolución de 1910, había más de mil empresas mineras en el país, y aproximadamente $70 \%$ de éstas eran de origen norteamericano (Tetreault, 2015; Urias, 1980).

Esta relación de sometimiento no ha cambiado. La transferencia y extracción de minerales hacia los países del Norte global son parte de un continuum del saqueo colonial, con la diferencia que hoy se realiza bajo el amparo del comercio internacional y el libre mercado (Delgado, 2010), promovidos por el capitalismo neoliberal. Al respecto, Zúñiga y González (2011) mencionan que solo durante la primera década del siglo XXI, en México, se extrajo el doble de oro y la mitad de la plata que la corona española atesoró en 300 años de conquista, de 1521 a 1821.

Ejemplo de tal saqueo es el caso de Minera San Xavier (MSX), filial subsidiaria de la empresa canadiense New Gold Inc., que en 1997 llegó a Cerro de San Pedro, San Luis Potosí, con un emprendimiento minero. Lo novedoso y controvertido del proyecto fue que la técnica de extracción, después de 400 años de explotación en este sector, debía ser a cielo abierto ${ }^{1}$, con implicaciones de destrucción y contaminación en el entorno. Las reservas fueron estimadas desde el inicio en 61,1 millones de toneladas, en cuya extracción se generaría 0,59 gramos de oro por tonelada y 23,9 gramos de plata por tonelada equivalente a 1,2 millones de onzas de oro y 47 millones de onzas de plata (Costero, 2008; 2015).

La empresa minera empezó a operar entre controversias jurídicas y la oposición social al proyecto ${ }^{2}$. Y aunque el fenómeno se ha estudiado desde diferentes enfoques, como desde la antropología, sociología o historia, las implicaciones de las relaciones de género en el escenario extractivo ${ }^{3}$ no han sido consideradas. Al respecto, Ulloa (2016) y Zorrilla, Sacher, Acosta y Báez (2012) señalan que hay muy poca información sobre el rol de las mujeres, su participación y las estrategias políticas, ambientales y territoriales que desarrollan en los contextos extractivos. En particular, hace falta un análisis sobre el extractivismo, despojo y las relaciones de género, ya que el poder que ellas pueden ejercer en las negociaciones y toma de decisiones son de menor valía para el patriarcado y capitalismo. Las mujeres al ser relegadas de los ambientes públicos y políticos, no participan en los convenios entre las mineras y las comunidades en igual condiciones que lo hacen los hombres, por lo que suelen ser ignoradas, minimizadas y utilizadas para beneficio del capital.

A partir de lo anterior, planteamos las siguientes preguntas: ¿cuál fue el papel de las mujeres en el despojo territorial e identitario producido por MSX en Cerro de San Pedro? ¿Cómo el capitalismo y patriarcado las utiliza, al desposeerlas de poder? Para dar respuesta a estas preguntas, se utiliza la perspectiva de género.

El documento se encuentra estructurado en cuatro secciones. La primera, el apartado teórico, permite entender el carácter histórico y colonial de las relaciones sociales de género y su articulación con la dimensión territorial de la megaminería y el despojo, desplegado por los dispositivos del sistema patriarcal

1 A diferencia de la minería tradicional o subterránea, donde los minerales se encontraban dispuestos en altas concentraciones en las llamadas "vetas", en la minería a cielo abierto, la extracción se realiza de forma totalmente superficial, debido a que estos se encuentran diseminados en pequeñas cantidades en grandes extensiones territoriales.

2 Para más detalles sobre el movimiento social antagonista al proyecto extractivo de MSX y sus estrategias políticas y de resistencia, pueden consultarse los trabajos de Martínez (2016), Lamberti (2010), Madrigal (2009) y Reyna (2009). Es importante señalar que estos no incorporan la perspectiva de género en sus análisis. Un acercamiento mediante el análisis de género puede leerse en Cortés, Zapata, Ayala y Rosas (2018).

3 La minería a cielo abierto o megaminería, nombrada así por la tecnología que utiliza y por los efectos devastadores que genera, se le considera una actividad extractiva, ya que hay un escaso o nulo procesamiento de los bienes naturales extraídos, por lo que no se le puede considerar una industria; se orienta básicamente a la gran transferencia de minerales de los países del Sur geopolítico hacia los países del Norte. 
que se imbrican y refuerzan con otros sistemas de dominación como el capitalismo, el extractivismo y el colonialismo. En la segunda, se describe la metodología utilizada para el levantamiento de la información en campo. En la tercera, se presentan los resultados de la investigación, donde se describen y analizan dos procesos de despojo: primeramente, la estrategia de negociación que MSX hizo entre ejidatarios/as para rentar una superficie del ejido y poder explotarlo, y posteriormente, el acuerdo de ocupación territorial donde la comunidad de La Zapatilla fue desplazada. Por último, se presentan algunas reflexiones a modo de conclusión.

\section{Entronque de patriarcados}

Segato (2016) menciona que en la aldea-mundo ${ }^{4}$ existían jerarquías claras de prestigio entre la masculinidad y feminidad, representadas por figuras que hoy podemos entender como hombres y mujeres; sin embargo, con la llegada de la empresa colonial-moderna en 1492, esa distancia se agrava y magnifica bajo el entronque de patriarcados. Este suceso histórico de encuentro entre el patriarcado precolonial y el occidental, derivó en desventura para las mujeres, ya que la opresión no solo vino con los colonizadores, sino que se entrecruzó con una versión propia de jerarquía (Paredes, 2008), con la opresión más antigua: las relaciones sexuales de dominación (Segato, 2014).

El cruce entre patriarcados que legitimizó la valorización diferencial entre los géneros, entró en contacto con el discurso igualitario de la modernidad y se transformó en un orden súper-jerárquico y desarraigado para las mujeres debido a: 1) transformación del espacio público ocupado ancestralmente por hombres, en una esfera pública que arrebata para ellas toda politicidad y a su vez se torna pretendidamente universal; 2) el derrumbe, la privatización y nuclearización del espacio doméstico, convertido ahora en resto y margen despojado de politicidad; y 3) la binarización de la dualidad que estructura el género, totalizando uno de sus dos términos constituido como público y universal, en oposición al otro, como privado, particular y marginal (Segato, 2015).
En un mundo invadido e intervenido por el frente colonial, los géneros ocupan en el ámbito comunitario espacios duales y recíprocos de la vida social; no obstante, con el advenimiento de la colonialmodernidad, el sujeto masculino es catapultado a la posición de sujeto universal y crea una binarización de estos espacios. Este es el proceso histórico del surgimiento de la esfera pública, en el que el espacio que fue público o masculino, mutó en la esfera pública o dominio universal (Segato, 2016).

Así, las relaciones desiguales de género se instauraron desde el proceso modernidad/colonialidad bajo ciertas dualidades, como naturaleza/cultura u hombre/mujer. A partir de estas, la naturaleza se feminiza y se asocia a nociones de valoración o desvalorización, conforme a contextos particulares, derivando en desigualdades sociales hacia las mujeres. Estas desigualdades se expresan en todos los ámbitos y procesos extractivos, específicamente en la minería $\mathrm{y}$ en las acciones de los diversos actores sociales que se interrelacionan, incluido el Estado (Ulloa, 2016).

\section{Territorio, despojo y género}

El territorio debe entenderse no solamente como un espacio biofísico o geográfico, sino también como espacio de vida social y corporal (Colectivo Miradas Críticas del Territorio desde el Feminismo, 2017); como un espacio por el que compiten las empresas mineras con la población local, debido a que contiene bienes naturales altamente explotables (Bebbington e Hinojosa, 2007; Pulido, 2015). En esa competición, las huellas que se imprimen en el territorio y en las subjetividades corporales, se experimentan de manera diferenciada conforme al género. Bermúdez, Zambrano y Roa (2014) señalan que esa diferenciación tiende a ocultarse y silenciarse, dado que entre género y territorio hay una relación estrecha, y la proporciona el hecho de que el género o la construcción social de identidades de género se dan desde algún sitio (Calvillo, 2012); es decir, se producen en un territorio determinado. Pero también es un lugar de despojo, donde a través de procesos violentos, se reconfiguran las áreas socioespaciales y, en particular, socioambientales,

4 Esta idea es utilizada a falta de un mejor nombre para representar las relaciones sociales antes de la intrusión colonial (Segato, 2016). 
limitando las capacidades que tienen las comunidades de decidir sobre sus medios de sustento y sus formas de vida (Ojeda, 2016).

El control de los bienes naturales que se encuentran en el territorio es un elemento clave para la minería, debido a que los derechos de propiedad de la tierra y las decisiones sobre su uso son fundamentales para las comunidades, por ser la base de la organización y toma de decisiones de los ejidos y colectividades agrarias. Desde la perspectiva de género, es evidente que las mujeres se encuentran relegadas de sus derechos agrarios, y que el acceso diferencial a la propiedad de la tierra es un factor estructural en la desigualdad de género en el medio rural (Salazar y Rodríguez, 2015). Tal como señalan Lastarria (2011) y Almeida (2012), en 1970, por cada cien ejidatarios solamente había una mujer sujeta de derechos agrarios, mientras que para el año 2007, de acuerdo con datos del Censo Ejidal, la cantidad de mujeres en el padrón ejidal ascendía a 20\%.

En los territorios de extracción minera, no solo se explota y despoja de la tierra en sí y sus minerales, sino del cuerpo de las personas como territorio conquistado y colonizado, especialmente el de las mujeres, el cual representa las desigualdades de poder, tanto en las decisiones personales, como sociales, políticas, económicas y culturales, porque “el despojo es el resultado de procesos violentos de expoliación, explotación y exclusión que se acumulan en el espacio y que entretejen múltiples escalas espaciales y temporales" (Ojeda, 2016, p. 22).

El término despojo, según David Harvey (2004a; 2004b), permite explicar cómo el capital, en su necesidad de reproducción, debe recurrir a un proceso de permanente saqueo, en donde el carácter predatorio de la expansión capitalista se refleja en procesos de mercantilización y privatización de la tierra, de acaparamiento de bienes comunes y de expulsión violenta de poblaciones campesinas, entre otros.
Sin embargo, a este despojo se suman procesos de dominación, subordinación y explotación, especialmente en el caso de las mujeres. Tal como lo señala Federici (2010), la subordinación de las mujeres y la separación de las esferas de la producción y la reproducción han sido centrales en los procesos de acumulación, donde no solo se despoja de la tierra, sino de sus derechos, medios de vida, el territorio, la territorialidad y la identidad.

\section{Metodología}

Este trabajo, que forma parte de uno más amplio (Cortés, 2017), se realizó entre mayo y junio de 2016 en Cerro de San Pedro 5 y la comunidad Nueva Zapatilla, a unos $20 \mathrm{Km}$ de la capital del estado de San Luis Potosí. Se utilizó un enfoque de investigación cualitativo a través de entrevistas semi-estructuradas y etnografía feminista ${ }^{6}$. Las entrevistas fueron hechas a 29 mujeres habitantes, ejidatarias, activistas y ex-activistas ${ }^{7}$ involucradas en el conflicto extractivo y afectadas por la ocupación territorial emprendida por MSX. El análisis feminista del despojo territorial e identitario se realizó mediante la transversalización de variables básicas de género y medio ambiente según propone Salazar (2017). Estas variables son: la división sexual del trabajo, el acceso diferenciado a los bienes naturales y a la toma de decisiones, tomando como referencia el concepto de territorio. Conforme a dicha transversalización, se muestra que las mujeres tuvieron nulo poder de decisión para que la corporación minera pudiera asentarse y extraer los metales; se aprovecharon de las estructuras patriarcales previas y actuales para reproducir un orden de género jerárquico que minoriza ${ }^{8}$ a las mujeres; por lo que sus territorios fueron invadidos y despojados y ahora ellas viven las consecuencias de un proceso en el que no fueron consultadas ni consideradas.

5 Cerro de San Pedro es el nombre del municipio donde se hizo la investigación, también el nombre de la cabecera municipal y del ejido que rentó parte de su extensión a MSX.

6 Castañeda (2012) menciona que "la etnografía feminista constituye un aporte central porque desprivatiza el mundo de las mujeres, dándole la relevancia que merece en cuanto que constitutivo e insoslayable en el análisis de cualquier cultura" (p. 224).

7 Algunas de ellas comparten el carácter de habitantes y ex-activistas, o solo son ejidatarias o habitantes. Para más información, puede consultarse Cortés (2017). Los nombres reales de las entrevistadas fueron cambiados a petición de ellas.

8 Minorizar, según Segato (2016), es un proceso donde a las mujeres se les trata como menores y sus intereses son confinados al ámbito íntimo, de lo privado, especialmente como tema de minorías y en consecuencia como tema minoritario. 


\section{Resultados y discusión}

\section{Arrendamiento del ejido Cerro de San Pedro: un asunto de hombres}

La dotación del ejido Cerro de San Pedro la hizo el Estado en 1926, concediendo la posesión definitiva de $1776,47 \mathrm{Ha}$ a 125 personas bajo el carácter de jefes/as de familia. De este número, 118 tenían jefatura masculina $(94,4 \%)$ y 7 femenina por viudez (5,6\%) (Medina, 2008, p. 249). Esta disparidad entre géneros se ha presentado desde el reparto inicial de la tierra, marcado por la desigualdad de la política agraria mexicana para las mujeres, la cual definía quién podía recibirla. Las mujeres históricamente han sido discriminadas, ya que únicamente podían acceder a la propiedad ejidal si tenían familia a su cargo, mientras que los hombres adultos podían obtenerla independientemente de la edad y si eran jefes de familia o no. Con esta disposición, se asume que la norma son los varones y que el derecho de ellos es equivalente al del núcleo familiar. Desde esta lógica patriarcal, fueron muy pocas las mujeres inscritas en los padrones de peticionarios/as de tierras y todavía menos las que recibieron dotación por parte del Estado mexicano (Rosas y Zapata, 2012; Vázquez, 1996).

En la dotación del ejido de Cerro de San Pedro, las estructuras patriarcales posibilitaron el posterior despojo realizado por MSX, ya que más del $90 \%$ de personas con derechos agrarios fueron hombres, por lo que se configuró un orden desigual de género en relación con la tenencia de los bienes sociales, que más tarde tendría repercusiones importantes en el despojo territorial de la propiedad ejidal.

La estructura y organización del ejido Cerro de San Pedro estuvo influida por las acciones que se tomaron desde la empresa American Smelting and Refining Company (Asarco), que en 1943 comenzó a trabajar en esas tierras. Posteriormente, se realizó una fusión mercantil entre Asarco y la Compañía Metalúrgica Mexicana, que realizaba trabajos de extracción en el lugar desde 1905. Sin embargo, en
1948 se tomó la decisión de que Asarco abandonara el ejido debido al estallido de una huelga obrera, por lo que la mayoría de los ejidatarios se desplazaron a la ciudad de San Luis Potosí o Monterrey en busca de fuentes de empleo (Lamberti, 2010; Medina, 2008; Reygadas y Reyna, 2008).

Después de la huelga de 1948, pocos/as ejidatarios/as permanecieron, por lo que la estructura de organización ejidal como tal se fue desvaneciendo. Fue hasta mediados de 1990, cuando esta volvió a cobrar importancia, dado que, para realizar sus actividades, MSX requería de 291,35 Ha del ejido Cerro de San Pedro. Para lograr sus propósitos, en 1997 los representantes de la empresa firmaron un contrato de arrendamiento con falsos ejidatarios ${ }^{9}$ pertenecientes a la comunidad La Zapatilla. En el documento se obligaba a las futuras autoridades ejidales a asegurar el arriendo y se estipulaba que no se requeriría su convalidación para mantenerlo (Herrera, 2010; Ortiz, 2009; Peña y Herrera, 2008).

Al mismo tiempo que en MSX se realizaban tales acciones, se organizó el Frente Amplio Opositor $\left(\mathrm{FAO}^{10}\right)$, movimiento social conformado por múltiples organizaciones con el fin de impedir el asentamiento de MSX en territorio potosino. En 2001, debido a que la minera había utilizado ejidatarios falsos, el FAO buscó a las personas que tuvieran familiares con derechos ejidales para que los reclamaran, y de esa forma bloquear el proyecto de la corporación minera. Desde el Tribunal Unitario Agrario se emitieron edictos para llamar a personas sucesoras de los/as ejidatarios/as que habían recibido la dotación desde 1926, con lo que comenzaron diversos juicios de sucesión.

En 2002, personas sucesoras de derechos ejidales iniciaron un proceso legal para denunciar el contrato realizado con los falsos ejidatarios. Hacia 2004 concluyó dicho juicio, donde el Tribunal Unitario Agrario del XXV Distrito decretó nulo el contrato de arrendamiento de 290 hectáreas de tierra ejidal, efectuado entre MSX y un presunto comisariado ejidal cuyo derecho de usufructo no fue probado.

9 La asamblea ejidal, que es el máximo órgano de gobierno en un ejido y cuyos integrantes toman las decisiones sobre este tipo de propiedad social, no se encontraba constituida legalmente, hecho del que se valió MSX para firmar un acuerdo con personas que no poseían el carácter legal de ejidatarias y así lograr la explotación de los recursos de la comunidad.

10 Fue una autodenominación del movimiento social, que no guarda relación con Food and Agriculture Organization of the United Nation. 
Ante esta decisión, desde la minera se buscó la forma de hacer prevalecer sus intereses, y una de sus estrategias fue promover la ocupación temporal de las tierras ejidales en pugna. La Dirección General de Minas de la Secretaría de Economía le concedido a MSX un permiso por 30 años, argumentando que la actividad minera era prioritaria, aun cuando en la Ley de Minas, en su artículo 20, restringe esta actividad en los núcleos poblacionales o donde hay restricciones ecológicas (Peña y Herrera, 2008; Toscana y Hesles, 2010), como ocurría en este caso.

Para lograr los permisos de ocupación temporal y servidumbre legal que MSX necesitaba, se comenzaron a promover derechos agrarios (tal como lo hizo el FAO en 2001) donde se incluía a las personas que habían firmado el contrato apócrifo y que quedaron bajo el estatus de posesionarias ${ }^{11}$. Pero, ¿cómo y por qué desde una minera, como empresa privada, se promueven derechos agrarios? ¿Si el Estado no es capaz de promover estos derechos, con qué intenciones lo hacen desde una empresa extranjera? El propósito fue claro: tener la tierra bajo control, manejarla deliberadamente y poder decidir sobre el uso y explotación del territorio, y que en la asamblea del ejido se pudieran tomar acuerdos conforme a los intereses que beneficiaran los objetivos de la minera. Sin embargo, ya con derechos ejidales, tras haberse constituido la asamblea en 2010, los nuevos ejidatarios no estarían conformes, por lo que solicitaron un amparo al Tribunal Superior Agrario y obtuvieron el fallo a su favor para negociar el contrato de arrendamiento de 2011, por considerar que la corporación les pagaba menor cantidad de dinero de la que debían recibir. Dicho contrato venció en el año 2016 y ascendió a cuatro millones de pesos; cantidad que se les otorgó anualmente y se repartió entre 66 personas.

Pero, ¿cómo fueron utilizadas las mujeres para que desde la minera pudieran despojarlas de sus territorios y territorialidades? ¿Cómo se manipularon sus decisiones? ¿Cómo su cuerpo despojado de derechos fue utilizado para el despojo territorial e identitario, no solamente de ellas sino también de los hombres? En la promoción de derechos ejidales que hicieron los funcionarios de MSX se incluyeron algunas mujeres, quienes aceptaron por las precarias condiciones en que vivían en el medio rural y no por interés de trabajar la tierra. En la empresa no tendrían ningún poder para promover derechos ejidales, sin embargo, al hacerlo les permitía tener a quién manipular y sobre todo, que por medio de aparente legalidad institucional, con la firma de mujeres y hombres ejidatarios, podían obtener el consentimiento local para desarrollar su actividad y materializar el despojo.

Estas acciones estratégicas de la minera, además se vieron cobijadas por dos aspectos centrales de las estructuras patriarcales que prevalecen en los ejidos: la tenencia de la tierra y la toma de decisiones, espacios en donde las mujeres tienen poca representatividad y participación, por tratarse de estructuras masculinas, ambas relacionadas con el despojo del cuerpo y del territorio.

De las 66 personas que conforman el ejido, 41 son hombres $(62,2 \%)$ y 25 mujeres $(37,8 \%)$ (aunque del año 2001 a 2010 cuando solo había siete personas ejidatarias, únicamente dos de ellas eran mujeres). La promoción de derechos ejidales que se hizo desde MSX, benefició a 23 mujeres y 36 sujetos masculinos más, a partir del año 2010. A pesar de que más mujeres se incluyeron como ejidatarias, se siguió manteniendo una clara desventaja para ellas, no sólo en número, sino en la capacidad de tomar decisiones sobre la ocupación y uso de la tierra.

Aparentemente el acceso a la tierra para ellas fue en condiciones similares a los hombres, sin embargo, los acuerdos importantes se tomaron por imposición masculina, debido a que estos se llevaron a la asamblea ejidal donde prevalece una estructura patriarcal y las decisiones que toman ellas pueden manejarse fácilmente. Tal como Solano (2015) menciona, los espacios de participación para las mujeres en las comunidades rurales son limitados, no tienen el mismo peso en la toma de decisiones que los hombres -quienes acaparan la representación comunitaria utilizando muchas veces figuras femeninas

11 Almeida (2012) señala que las posesionarias, son una nueva figura agraria a partir de la modificación a la Ley Agraria en 1992. Las autoridades ejidales les reconocen como propietarias por medio del certificado de titulación de las tierras parceladas; no obstante, no tienen derecho a las tierras de uso común, ni a la dotación de solares, a diferencia de las ejidatarias. 
dóciles para su manipulación-, y sus necesidades son las menos atendidas. En esas condiciones, cuando desde una empresa minera se adueñan de territorios vía concesiones por parte de los Estados, violan los derechos como el de la autodeterminación, y no son tomadas en cuenta las opiniones, aspiraciones, posiciones y exigencias de las mujeres de comunidades despojadas. Así lo expresan Delfina y Cecilia:

Pues casi siempre son los hombres, que son los que andan más por delante. Son los que deciden y los que dicen. Casi nosotros no opinamos. Y por lo mismo, como casi no opinamos las mujeres, como que nos ignoran lo que las mujeres dicen (Delfina, ejidataria de 33 años).

Pues a veces participan en la planilla, aunque sea de suplentes, porque todavía no he sabido que sea alguna mujer comisariada ${ }^{12}$, secretaria sí, pero comisariada no. Comisariado siempre lo dejan a alguna persona que tenga capacidad, que sea hombre. Aunque las mujeres también pueden ya en este tiempo, también tienen inteligencia y buenas decisiones, pero todavía a veces sí se impone el hombre, pues yo creo que porque son mayoría los hombres ejidatarios, ¿verdad?, y ellos lo deciden porque son menos mujeres ejidatarias que hombres, ellos deciden (Cecilia, habitante de 61 años).

Como se observa, la promoción de derechos agrarios realizada desde MSX obedece a los intereses extractivos de la corporación, hecho que se torna preocupante pues desde la minera se utiliza su poder económico para tener injerencia en las decisiones comunitarias sobre los bienes sociales. En el caso de las ejidatarias, los funcionarios de la empresa recurren a ellas para ganar consenso, pero al mismo tiempo generan un proceso de doble subordinación; el primero, respecto a sus propios intereses económicos, y el segundo, en relación con los ejidatarios en la asamblea que es un espacio generizado, ya que utilizan su voto, pero no les dan voz a las mujeres.

La convención patriarcal mayoritaria de la asamblea ejidal provocó que la opinión femenina en el ejido no se manifestara ante la imposición capitalista y patriarcal, pues es esta última la que simbólicamente otorga legitimidad y es considerada como la totalidad, la que puede tomar decisiones y, al mismo tiempo, formula imaginarios que son considerados como válidos. Tal y como menciona Segato (2018), lo que enmascara la centralidad en las relaciones de género es el carácter binario de la estructura que torna la esfera pública englobante, totalizante, sobre y a expensas de su otro residual: el dominio privado, personal, o sea, la relación entre la vida política y la extra-política. Ese binarismo define la materialidad de un universo cuyas verdades son dotadas de valor universal e interés general y cuya enunciación es imaginada como emanada de la figura masculina, y sus otros, concebidos como particulares, marginales o minoritarios.

Además, el hecho de que ellas no sean consideradas en las decisiones relacionadas a las labores de la tierra y la minería, está estrechamente relacionado con la rígida división sexual del trabajo, donde las cuestiones del ejido forman parte de la esfera pública. Mientras su contraparte femenina se supone debe estar recluida en la esfera privada, dedicándose exclusivamente al trabajo doméstico.

Solamente escuchando porque al menos yo no entiendo de eso, que pues yo, mi esposo era de aquí y yo soy de Ciudad Mante. Y nomás como me tocó mi suerte con mi esposo aquí y pues él era el ejidatario y él era quien sabía de eso (Ofelia, ejidataria de 65 años).

Nomás oyendo, pero le voy a decir una cosa, en veces uno no les entiende. Y pos nada más firmando el libro de asistencia, y aparte otra cuando nos retiramos y una hoja aparte que, esa se quedará yo creo el comisariado ejidal. Nada más eso, no hacemos nada más, que estar sentadas como estoy aquí (Edith, ejidataria de 75 años).

La predominancia masculina y la poca participación femenina en la asamblea es consecuencia de un reparto ejidal inicial mayormente masculino, ya que solo las mujeres, cuando eran madres solteras o viudas con hijos menores podían recibir tierra (Lastarria, 2011). Este tipo de organización es denominado por Lagarde (1996) como organización social genérica, que deriva de establecer el sexo como categoría para designar actividades, funciones, relaciones y poderes puntuales, es decir, géneros; la

12 Se refiere a la figura jurídica que preside el comisariado ejidal; uno de los órganos ejidales de gobierno. 
organización social genérica es la dimensión social basada en la sexualidad de las personas. Se trata de una red estructurada de poderes, jerarquías y valores que se configuran dependiendo de la magnitud de un poder, el cual aumenta directamente en la medida que resta de otro, despojando el cuerpo de las mujeres de poder de decisión.

Se pone de manifiesto que la asamblea ejidal se configura como un espacio de inequidad emanado de relaciones sociohistóricas de poder entre hombres y mujeres, donde el disciplinamiento ha sido parte de su construcción, posicionando a los varones en el plano público en el que se toman las decisiones, y a las mujeres en el plano de la invisibilidad y contención que niega sus voces y opiniones. Desde la MSX se aprovechó la estructura patriarcal de la asamblea, donde las mujeres fueron utilizadas y debieron responder a los intereses de quien les otorgó el carácter de ejidatarias. Al mismo tiempo, existe un control operado por parte de la minera a través de los hombres ejidatarios, ya que son ellos quienes, por ser mayoría, conducen la asamblea ejidal conforme a los deseos de la corporación. Es decir, tanto el capitalismo a través de la minera como el patriarcado a través de la imposición de las decisiones masculinas acentúan la condición de subordinación de las mujeres, sin tomarlas en cuenta, pero afectándolas en sus vidas cotidianas al despojarlas de sus derechos, medios de vida, territorios y parte de su identidad, y favoreciendo el logro de los propósitos de la minera.

Tanto el acceso diferenciado a la propiedad de la tierra como la participación de las mujeres sobre la explotación del ejido Cerro de San Pedro, dan cuenta de que el género influye como un factor determinante de desigualdad en el contexto extractivo minero. No se trata de que únicamente sean ejidatarias y reciban un pago en dinero, sino que deberían haber sido sujetas de derechos políticos, con la posibilidad de incidir conscientemente sobre el destino del núcleo agrario. Lo cual implicaba estar informadas constante y conscientemente, tener voz e influir a partir de conocer las repercusiones que tendría el despojo que haría la minera y que debía explicarse y analizarse en la asamblea ejidal, pero las estructuras patriarcales y capitalistas no lo permitieron.

$\mathrm{Al}$ igual que se dio la imposición masculina para el consentimiento del arrendamiento del ejido a la MSX, ocurrió una situación similar con las mujeres en el desplazamiento de la comunidad La Zapatilla, como a continuación se expone.

\section{EI desplazamiento de La Zapatilla}

La Nueva Zapatilla es un asentamiento aledaño del municipio Cerro de San Pedro, y se encuentra sobre uno de los costados del Cerro de los Gatos. Es un conjunto de 45 viviendas, con una población de 115 personas que hasta 2001 vivían en lo que ahora es llamado la Vieja Zapatilla. Era un caserío en torno a lo que en el pasado fue una hacienda de fundición, que alojaba inmuebles como la denominada Casa Guadalupe, construidos entre los siglos XVII y XVIII (Madrigal, 2014). La Zapatilla fue desplazada para que se construyera allí parte de la infraestructura de MSX para el proceso de separación de los minerales: los patios o piletas de lixiviación ${ }^{13}$.

Las entrevistadas describieron a la antigua $\mathrm{Za}$ patilla como un lugar donde las viviendas estaban construidas mayormente de manera rústica, dispuestas de forma discontinua, a diferencia del lugar en el que viven ahora, donde las casas se encuentran contiguas unas de otras, y la separación más notable es el camino que lleva a las comunidades de Portezuelo y Cuesta de Campa. Es decir, la MSX produjo un cambio para apropiarse territorialmente a partir del desplazamiento y despojo de su territorialidad, del apego que tenían a su forma de vida y su identidad. Los elementos comunitarios fueron sustituidos por otros que pertenecen más a la vida urbana del Valle de San Luis Potosí, apelando a un discurso que les prometía tener mejores casas, servicios y condiciones de vida.

La casa de nosotros estaba hecha de pura roca, nada más el piso de tierra, en la de nosotros no había piso, incluso estaba techada de garrocha y la otra parte era de lámina. El pueblo pues era así, había garambullos, un tanque grandísimo con sus árboles, la iglesia era muy pequeña. El tanque, de

13 Esta infraestructura es donde se realiza la separación de los minerales de la roca triturada, por medio de sustancias químicas como el cianuro. 
ahí tomábamos agua. Me acuerdo que había animales y también tomaban de ahí, caballos, hasta se metían al agua. Era un rancho, rancho. La plaza también era muy pequeña. Algunas de piedra y otras de garrocha. Algunas tenían de loza, depende de cada familia. Había de loza, de garrocha, de lámina, y pisos, a veces sin piso de pura tierra, otros de puro piso firme, y otros de cemento muy suave. Nomás había como una o dos casas que tenían todo adentro y las demás eran la cocina aparte, los cuartos aparte. Había una casa grandísima de una señora que se llama doña Beatriz, había como ocho cuartos, pero separados. Incluso también separados y tenían un patio grandísimo. Algunas estufas de gas, otras de chimenea, de pura leña, en mi casa era de pura leña. La mayoría eran de leña (Elisa, habitante de 32 años).

Las entrevistadas mencionaron que, aunque su antigua comunidad careciera de ciertos servicios y no tuvieran las "comodidades" que ahora poseen, la extrañan y se sentían mejor viviendo allá, ya que el espacio era abierto y las personas vecinas no estaban al pendiente de la vida ajena, porque las plantas del campo eran altas y las casas no podían verse a simple vista. La ejidataria Leonor señaló que se "sentía más a gusto, aunque viviera debajo de un tejabán ${ }^{14 \text { " }}$ y la ejidataria Luisa indicó que sintió tristeza al dejar su antigua casa, porque la habían construido con el esfuerzo de su trabajo. Los sentimientos que se expresan en los testimonios reflejan parte de los efectos que produce el despojo tanto del territorio en sí mismo, como de sus medios de vida y la territorialidad, en donde se ven comprometidos sus apegos e identidad territorial. Al respecto, Bermúdez et al. (2014) señalan que los reasentamientos, más que otorgar una compensación por los daños ambientales a las comunidades u ofrecer mejoría en la vida de la población, son formas de expropiación del territorio a favor del extractivismo, ya que, en el mejor escenario, se sustituye un territorio por otro; sin embargo, el restablecimiento provoca que la identidad y la memoria desaparezcan, pues el espacio y las relaciones cambian fuertemente de forma.

La relación que las mujeres guardaban con su antiguo territorio, es decir, su territorialidad, cambió con el desplazamiento de la comunidad; la manera en que ellas lo percibían y donde residía parte de su identidad, además de su representación física, socioeconómica e identitaria, se transformó completamente a causa de la sustitución de un territorio por otro, sobre todo porque el espacio de la casa es parte importante de la identidad de género de las mujeres, al ser el espacio asignado y vivido desde su posición como mujer.

La negociación sobre el desplazamiento de la comunidad -a una distancia inferior a medio kilómetro del lugar original-, fue acordada y llevada a cabo por los hombres y representantes de MSX, cuando la empresa recientemente había llegado al territorio sampedrense. Sobre este tipo de decisiones, Martínez (2013) argumenta que donde los emprendimientos mineros consiguen asentarse, uno de los principales problemas para las mujeres es la fuerte discriminación en la toma de decisiones, ya que estas no son consultadas en los procesos de negociación que se hacen de manera opaca. Así lo mencionaron en entrevista las ejidatarias habitantes de la Nueva Zapatilla:

[Los que decidieron fueron] los hombres, porque uno de mujer, no... ellos, los hermanos, los sobrinos, ellos estuvieron de acuerdo en que nos dieran aquí, porque según esto si nosotros teníamos una hectárea, según esto le daban una media hectárea, o si teníamos media nos daban media y así. Eso fue un acuerdo de ellos. Ellos eran los que hablaban. Ya nomás él me decía, vamos a vivir aquí, y yo estaba en la creencia que era allá mismo, pero no, que porque nos habían regalado este pedacito (Leonor, ejidataria de 55 años).

No pues es que eso solamente mi esposo, porque él era solamente el que andaba, los hombres eran, nosotros no nos parábamos allá para nada. Ellos son los que sabían en lo que iban a trabajar y todo. Pues yo pienso que así eran todos aquí, todos los hombres aquí de machistas. Y pus uno de mujer tenía que ser uno sumisa a lo que ellos dijeran (Ofelia, ejidataria de 65 años).

El nulo dominio sobre los derechos de propiedad puso nuevamente a las mujeres en una posición marginal en el proceso de negociación para el desplazamiento, dirigido por los varones de la

14 Construcción rústica y modesta, usualmente hecha de teja o lámina de zinc. 
comunidad y pactado con representantes de MSX. A esta alianza entre las élites masculinas colonizadoras y los hombres de los pueblos que se busca colonizar, se considera como un pacto llevado a cabo entre el patriarcado central y el patriarcado dependiente (De Assis, 2016), donde el machismo es un elemento que conecta a hombres blancos, mineros, urbanos y profesionales con hombres campesinos rurales. Muchas de las pláticas "informativas" y acuerdos sobre un proyecto minero se plantean en los términos "de hombre a hombre" (Silva, 2017), sin considerar la voz de las mujeres, pero afectándolas en todos los ámbitos de su vida cotidiana.

La falta de control y suprimido poder de decisión de las mujeres habitantes de La Zapatilla sobre el uso del territorio y el desplazamiento que vivieron resulta evidente en sus testimonios. Al respecto, Salazar y Rodríguez (2015) señalan que las restricciones de las mujeres sobre el control del territorio son impuestas por un sistema patriarcal que se reproduce a través de las generaciones, mediante una serie de valores culturales auto-asumidos por ellas mismas, como la aceptación de roles de género estereotipados, una estricta división sexual del trabajo y la exclusión de las mujeres de la toma de decisiones, tal como se advierte en el siguiente testimonio:

Pues yo ni sabía nada porque mi esposo era el que, pues ya ve que más antes había muchos esposos que nada más ellos tenían voz y voto, uno casi no. Uno nunca se metía en eso, o sea ellos hicieron [...] pero como a él casi, mi esposo nunca le gustaba que yo le anduviera preguntando, no le gustaba, él sólo hacia sus tratos, él hacía y deshacía, y uno, pos yo nomás miraba, oía y a veces ni oía, porque pos como ellos eran hombres pos allá iban, hacían sus juntas y todo eso. Por eso yo casi de eso mucho no, pos no le puedo dar mucha información, porque pos ellos hacían las cosas, sus tratos [...] no me parecía muy bien, porque sí deberían de haberle tomado a uno en cuenta, decirme: oyes, ¿cómo ves?, o bueno, y no nomás él, casi la mayoría de todos los señores, y bueno, solamente que [a] las demás señoras sí les haigan platicado, hayan quedado de acuerdo, pero pos a mí no [...] yo nada, nada, nada. Mi esposo era el que se entendía de todo. Yo nada. Yo nada más como dice el chiste, pos yo nomás miraba. Veía y miraba [...] ¡Ay, ¡tú qué sabes! ¡Tú qué sabes! Yo no decía nada (Luisa, ejidataria de 66 años).
El nulo poder de decisión sobre la reubicación de La Zapatilla representa una de las situaciones más usuales, más no aceptable, en las relaciones sociales entre mujeres y hombres, que tiene que ver con el sujeto masculino emergido de la modernidad y el consecuente androcentrismo, expresión única y válida en el sistema patriarcal. De acuerdo con Facio (2012), esta es una de las manifestaciones del sexismo que consiste en tomar al varón como referente único de lo humano y su perspectiva como el punto de vista de la humanidad. Bajo esta forma de sexismo, lo masculino se erige como la principal experiencia humana, mientras que lo femenino es entendido como lo otro, lo específico y particular.

La verdad nada. Como que es que aparte eran otros tiempos de que el señor de familia decía lo que se tenía que hacer. Y si él decidía y uno nada más escuchando. Ya nada más cuando venía a ver el lugar que se iba a fincar y ya cuando estaban trazadas igual venía a verlas, pero como te digo, él era el que tomaba la decisión. Ni yo, ni mi suegra tomamos parte de esa decisión, ni los hijos. Pero sí deberían de haber tomado la opinión [de las mujeres] (Elisa, habitante de 32 años).

Sobre este proceso de negociación exclusivamente entre hombres, García (2017) menciona que el extractivismo favorece la reconfiguración de espacios de interlocución y toma de decisiones masculinizados. A la par, la falta de consulta a las mujeres representa una violación a sus derechos patrimoniales, que se encuentran relacionados con un papel tradicional de género asociado al espacio privado, doméstico y dispuesto únicamente para el cuidado familiar, es decir, la casa; espacio en el que, en este caso, tampoco tuvieron voz ni voto, ni incidencia en la reubicación.

En los dos casos, tanto en la renta del ejido Cerro de San Pedro y el desplazamiento de La Zapatilla, es claro que el acceso a la propiedad de la tierra o una porción del territorio permite el acceso al poder real de las dirigencias o de liderazgos (Silva, 2017); es decir, permite controlar la propia vida, los intereses personales, el querer ser y sus posibilidades en el territorio; además de desarrollar autonomía propia, tener decisiones libres y no encontrarse sujetas a la dominación masculina de sus parejas, decidir sobre 
sus intereses y poder romper la subordinación, situaciones que no se presentaron en este caso.

Si se hace la comparación entre la renta del ejido y el desplazamiento de La Zapatilla, es posible afirmar que ambos sucesos coexistieron en desventaja para las mujeres, donde en el primero se les invisibilizó, pero al mismo tiempo se recurrió a su "voto sin voz" para consensuar y aceptar que la minera entrara al núcleo agrario. Mientras que, en el segundo, las voces, los intereses y los deseos de las habitantes de La Zapatilla simplemente no fueron tomados en cuenta.

Finalmente, la megaminería en Cerro de San Pedro reforzó las relaciones tradicionales de género, pues el capitalismo no puede desligarse del colonialismo ni del patriarcado; los tres se retroalimentan (Ayala, Zapata y Cortés, 2017). Tal como señala el Colectivo Miradas Críticas del Territorio desde el Feminismo (2017), el extractivismo provoca una repatriarcalización del territorio, dado que conforma en los territorios un nuevo orden patriarcal que converge y se apuntala en relaciones machistas previas, y profundiza y reactualiza las existentes. Así, el extractivismo minero utiliza a mujeres y hombres, de diferente manera, para despojarlos de sus territorios y medios de vida, siendo las mujeres quienes se encuentran en mayor desventaja debido a que además de enfrentar la colonialidad y discriminación por ser pobres-rurales, también se enfrentan a un patriarcado que se encuentra inmerso tanto en las relaciones personales (con sus parejas y otros varones de su familia) como en las negociaciones que se establecen en los ejidos y en la toma de decisiones ante las corporaciones extractivas. Ellas, al representar un cuerpo despojado de poder ${ }^{15}$, pueden ser más fácilmente despojadas de sus territorios e identidades por el capitalismo.

\section{Reflexiones finales}

Tanto en la ocupación del territorio ejidal como en el desplazamiento de la comunidad La Zapatilla, las mujeres tuvieron un papel minorizado en el proceso de negociación con los representantes de la MSX. En el caso del ejido Cerro de San Pedro, la posición de las mujeres ante las estructuras patriarcales fueron utilizadas para que la empresa obtuviera el permiso para realizar el trabajo minero, ya que no hubo una decisión plena y consciente sobre el uso del territorio, debido a que tuvieron que seguir los mandatos impositivos planteados desde MSX, los cuales las promovieron como ejidatarias y las ubicaron en un espacio estructurado históricamente conforme al género, reproducido en la asamblea ejidal. En el caso de la reubicación de La Zapatilla, el convenio se hizo con los hombres jefes del hogar, donde estos no consultaron a sus esposas y familias para decidir el cambio de la residencia familiar. Lo que pone de manifiesto el nulo poder de decisión que las mujeres han tenido en la ocupación del territorio sampedrense. Además de no considerar sus necesidades, arraigo, identidad y relación que ellas guardaban con su territorio y sus medios de subsistencia.

En ambos casos, el extractivismo minero se apuntaló sobre estructuras capitalistas y patriarcales previas y actuales que posibilitaron el despojo territorial, reproduciendo, ampliando y refuncionalizando un orden jerarquizado conforme al género, en donde la ocupación territorial que involucró el arrendamiento del ejido Cerro de San Pedro y el desplazamiento de la comunidad La Zapatilla fue negociado por los hombres de la comunidad privilegiando la experiencia masculina, mientras que la femenina experimentó un proceso de minorización e invisibilización. Para lograr el despojo de los territorios, capitalismo y patriarcado se vieron favorecidos tanto de los cuerpos despojados de poder de decisión en aspectos públicos y privados (la tierra, su participación política, la toma de decisiones); así como del despojo territorial, por lo que son aún más despojadas de lo poco que les quedaba: su voz de decisión y el control que pudieran tener en el espacio privado de la casa.

15 Consideramos a los cuerpos despojados de poder como aquellas subjetividades y corporalidades femeninas que les han negado la posibilidad de vivir dignamente en el territorio, al desposeerles de los elementos básicos que permiten sostener la vida humana y de aquellos estratégicos que les otorgan el carácter político de sujetas: agua limpia, un ambiente respirable y libre de contaminación, patrimonio familiar y comunitario, la palabra y su reconocimiento como interlocutoras; representan un cuerpo que es desplazado y sujetado por los intereses económicosextractivistas y delineado por procesos de subjetivación que justifican la minería y que, sin embargo, perviven día a día. 
Mientras los hombres mantienen el privilegio de la esfera pública y sus recursos materiales y simbólicos -como la tenencia de la tierra-, la posesión de la propiedad particular y el poder de toma de decisiones sobre ellas, o la propia capacidad de ser escuchados, las mujeres no tienen control sobre los bienes sociales o familiares, y menos aún sus palabras y deseos, que fueron minorizados en la relación establecida para negociar el asentamiento y operación de la MSX, pues esta se materializó a través de un sistema de usos y costumbres machista y sexista.

El uso de la variable de género para analizar el extractivismo permite mostrar que el acceso a los bienes en el territorio y el territorio per se, se encuentra determinado por un sistema social que utiliza como único distintivo la construcción social y cultural de la diferencia sexual, el cual crea, recrea y perpetúa privilegios masculinos y mantiene amplias limitaciones para ellas. Es así como las priva de derechos políticos que impiden las posibilidades de una vida plena, sin violencia y en un territorio libre de contaminación y del expolio capitalista de las condiciones que permiten sostener la vida comunitaria.

Además, al retirarse la minera, tanto ellas como otros integrantes de sus familias han quedado con un territorio destruido. Lo que resultó luego de la explotación minera fue un territorio intervenido por los dispositivos del saqueo; un socavón de un kilómetro de diámetro y 70 metros de profundidad ${ }^{16}$, a escasos 200 metros de la cabecera municipal, en donde no podrá prosperar ninguna actividad productiva como la agricultura o el pastoreo de animales. A esto se suma que perdieron el territorio que les dio identidad.

\section{Referencias bibliográficas}

Almeida, Elsa. (2012). Ejidatarias, posesionarias, avecindadas. Mujeres frente a sus derechos de propiedad en tierras ejidales de México. Estudios Agrarios, (52), 13-57.

Ayala, María del Rosario., Zapata, Emma., y Cortés, Ramón. (2017). Extractivismo: expresión del sistema capitalista-colonial-patriarcal. Ecología Política. Cuadernos de Debate Internacional, (54), 60-64.

16 Información proporcionada en el módulo de información de MSX.
Bebbington, Anthony., e Hinojosa, Leonith. (2007). Conclusiones: minería, neoliberalización, reterritorialización en el desarrollo rural. En Anthony Bebbington y Leonith Hinojosa (Eds.), Minería, movimientos sociales y respuestas campesinas (pp. 281-314). Perú: IEP: CEPES.

Bermúdez, Rosa., Zambrano, Karol., y Roa, Lilia. (2014). Los territorios, la minería y nosotras: las mujeres nos preguntamos. Colombia: Censat Agua Viva-Amigos de la Tierra.

Calvillo, Miriam. (2012). Territorialidad del género y generidad del territorio. En María Reyes y Álvaro López (Coords.), Explorando territorios. Una visión desde las ciencias sociales (pp. 263-293). México: UAM-X.

Castañeda, Martha. (2012). Etnografía feminista. En Norma Blazquez, Fátima Flores y Maribel Ríos Ríos (Coords.), Investigación feminista. Epistemología, metodología y representaciones sociales (pp. 217238). México: UNAM.

Colectivo Miradas Críticas del Territorio desde el Feminismo. (2017). (Re) patriarcalización de los territorios. La lucha de las mujeres y los megaproyectos extractivos. Ecología Política. Cuadernos de Debate Internacional, (54), 65-69.

Cortés, Ramón. (2017). Megaminería y género. El costo del oro para las mujeres de Cerro de San Pedro, San Luis Potosí (tesis de maestría). Colegio de Postgraduados, Texcoco, México.

Cortés, Ramón., Zapata, Emma., Ayala, María., y Rosas, Rocío. (2018). Miradas de género hacia el interior del movimiento socioambiental Frente Amplio Opositor a Minera San Xavier. Intersticios. Revista Sociológica de Pensamiento Crítico, (12), 35-49.

Costero, María. (2008). Minera San Xavier, San Luis Potosí: un estudio desde un punto de vista internacional. En María Costero (Coord.), Internacionalización económica, historia y conflicto en la minería. El caso de Minera San Xavier (pp. 59101). México: El Colegio de San Luis A.C.

Costero, María. (2015). La responsabilidad social corporativa de empresas mineras canadienses en el estado de San Luis Potosí, México. En Moisés Gámez (Coord.), Minería y capital transnacional sobre un territorio en riesgo. Análisis interdisciplinario sobre el Sitio Sagrado Natural de Wirikuta (pp. 189-220). México: El Colegio de San Luis A.C.

De Assis, Danilo. (2016). Ciencia en práctica. La emancipación de las mujeres indígenas (tesis doctoral). Universidad Nacional Autónoma de México, Ciudad de México, México. 
Delgado, Gian. (2010). América Latina y el Caribe como reservas estratégicas de minerales. En Gian Delgado (Coord.), Ecología política de la minería en América Latina (pp. 17-58). México: Universidad Nacional Autónoma de México.

Facio, Alda. (2012). Diccionario de la transgresión feminista. Costa Rica: JASS Asociadas por lo justo.

Federici, Silvia. (2010). Calibán y la bruja. Mujeres, cuerpo y acumulación originaria. España: Traficantes de Sueños.

García, Miriam. (2017). Petróleo, ecología política y feminismo. Una lectura sobre la articulación de Mujeres Amazónicas frente al extractivismo petrolero en la provincia de Pastaza, Ecuador (tesis de maestría). FLACSO-Ecuador, Quito, Ecuador.

Harvey, David. (2004a). El nuevo imperialismo (Juan Mari Madariaga, Trad.). Nueva York, U.S.A.: Oxford University Press. Edición Akal (obra original publicada en 2003).

Harvey, David. (2004b). The 'New' Imperialism: Accumulation by Dispossession. Socialist Register, (40), 63-87.

Herrera, Edna. (2010). Federalismo y ámbitos de competencia en México. Estudio de caso de Minera San Xavier en Cerro de San Pedro, S.L.P. 1994- 2009 (tesis de maestría). El Colegio de San Luis A.C., San Luis Potosí, México.

Lagarde, Marcela. (1996). Género y feminismo: desarrollo humano y democracia. España: Horas y Horas.

Lamberti, María. (2010). Una lucha a cielo abierto. El caso del Frente Amplio Opositor a Minera San Xavier (tesis de maestría). Flacso-México, México.

Lastarria, Susana. (2011). Las mujeres y el acceso a la tierra comunal en América Latina. En Patricia Costas (Coord.), Tierra de Mujeres. Reflexiones sobre el acceso de las mujeres rurales a la tierra en América Latina (pp. 19-38). Bolivia: Coalición Internacional para el Acceso a la Tierra.

Madrigal, David. (2009). "La naturaleza vale oro": riesgos ambientales y movilización social en el caso de la empresa minera canadiense New Gold/Minera San Xavier en México (tesis de doctorado). El Colegio de México, México.

Madrigal, David. (2014). Conflictos y no conflictos en el valle de San Luis Potosí. Análisis de la dimensión conflictiva de lo socioambiental a partir de dos casos. En María Paz y Nocholas Risdell (Coords.), Conflictos, conflictividades y movilizaciones socioambientales en México: problemas comunes, lecturas diversas (pp. 59-89). México: CRIM/Porrúa.
Martínez, Eider. (2013). Minería metalífera a gran escala. Impactos socioeconómicos de género en y cargas agregadas a las mujeres. Mujeres por la selva. Recuperado de https://mujeresporlaselva.wordpress. com/2013/06/06/mineria-metalifera-a-gran-escalaimpactos-socio-economicos-de-genero-y-cargasagregadas-para-las-mujeres/.

Martínez, Ulises. (2016). "Hemos hecho de todo, hemos intentado todo lo que te puedas imaginar": decisiones estratégicas del Frente Amplio Opositor a Minera San Xavier (tesis de maestría). FLACSOMéxico, México.

Medina, René. (2008). Sobrevivir en un pueblo minero. Vida cotidiana en Cerro de San Pedro, San Luis Potosi durante la posrevolución (tesis de maestría). El Colegio de San Luis A.C. San Luis Potosí, México.

Ojeda, Diana. (2016). Los paisajes del despojo: propuestas para un análisis desde las reconfiguraciones socioespaciales. Revista Colombiana de Antropología, (52), 19-43. doi: 10.22380/2539472X38.

Ortiz, José. (2009). La batalla por Cerro de San Pedro. Historias de la resistencia contra una minera canadiense. México: Ediciones Debajo del Agua.

Paredes, Julieta. (2008). Hilando fino desde el feminismo comunitario. Bolivia: Comunidad de Mujeres Creando Comunidad y CEDEC.

Peña, Francisco, y Herrera, Edna. (2008). Litigio de Minera San Xavier: una cronología. En María Costero (Coord.), Internacionalización económica, historia y conflicto ambiental en la minería. El caso de Minera San Xavier (pp. 173-200). México: El Colegio de San Luis A.C.

Pulido, Alejo. (2015). Los territorios frente a la minería. Debates y alternativas alrededor de la problemática minera en Colombia. Colombia: CEDINS.

Reygadas, Pedro., y Reyna, Óscar. (2008). La batalla por San Luis: ¿el agua o el oro? La disputa argumentativa contra Minera San Xavier. Estudios Demográficos y Urbanos, (2), 299-331.

Reyna, Óscar. (2009). Oro por cianuro: arenas políticas y conflicto socioambiental en el caso Minera San Xavier en Cerro de San Pedro (tesis de maestría). El Colegio de San Luis A.C. San Luis Potosí, México.

Rosas, Rocío.,y Zapata,Emma. (2012). Mujeres y tenencia de la tierra en Salvatierra, Guanajuato. Ra Ximhai, (2), 213-230. doi: 10.35197/rx.08.02.e.2012.19.rr.

Salazar, Hilda. (2017). El extractivismo desde el enfoque de género: una contribución en las estrategias para la defensa del territorio. Sociedad y Ambiente, (13), 3557. doi: 10.31840/sya.v2017i13.1754. 
Salazar, Hilda., y Rodríguez, Maritza. (2015). Miradas en el territorio. Cómo mujeres y hombres enfrentan la minería. México: Heinrich Böll Stiftung.

Segato, Rita. (2014). La perspectiva de la colonialidad del poder. En Zulma Palermo y Pablo Quintero (Comps.), Aníbal Quijano. Textos de Fundación (pp. 10-41). Buenos Aires, Argentina: Ediciones del Signo, Colección El desprendimiento.

Segato, Rita. (2015). Género y colonialidad: del patriarcado de bajo impacto al patriarcado moderno. En Marisa Belausteguigoitia y María. Saldaña (Coords.), Des/posesión: género, territorio y luchas por la autodeterminación (pp. 321-350). México: UNAM.

Segato, Rita. (2016). La guerra contra las mujeres. España: Traficantes de Sueños.

Segato, Rita. (2018). Manifiesto en cuatro temas. Critical Times Journal, 1(1), 212-225.

Silva, Rocío. (2017). Mujeres y conflictos ecoterritoriales. Impactos, estrategias, resistencias. Entrepueblos, Perú: CMP Flora Tristán, Coordinadora Nacional de Derechos Humanos.

Solano, Lina. (2015). Mujer, violencia e industria minera. Frente de Mujeres Defensoras de la Pachamama. Recuperado de http://defensoraspachamama. blogspot.mx/2015/08/mujer-violencia-e-industriaminera-1.html.

Tetreault, Darcy. (2015). México: la ecología política de la minería. En Henry Veltmeyer y James Petras (Coords.), El neoextractivismo. ¿Un modelo posneolineral de desarrollo o el imperialismo del siglo XXI? (pp. 253-279). México: CRÍTICA.

Toscana, Alejandra., y Hesles, José. (2010). El tesoro del Cerro de San Pedro. Fricciones locales-globales (1996-2009). En Carlos Rodríguez, Luciano Concheiro y María Tarrío (Coords.), Disputas territoriales. Actores sociales, instituciones y apropiación del mundo rural (pp. 153-184). México: Universidad Autónoma Metropolitana.

Ulloa, Astrid. (2016). Feminismos territoriales en América Latina: defensas de la vida frente a los extractivismos. Nómadas, (45), 123-139. doi: 10.30578/nomadas.n45a8.

Urias, Homero. (1980). ¿Quién controla la minería mexicana?. Comercio Exterior, (9), 951-963.

Vázquez, Verónica. (1996). Donde manda el hombre, no manda la mujer. Género y tenencia de la tierra. Cuadernos Agrarios, (13), 63-83.

Zorrilla, Carlos., Sacher, William., Acosta, Alberto., y Báez, Michelle. (2012). 21 preguntas para entender la minería del siglo XXI. Biblioteca Jurídica Virtual del Instituto de Investigaciones Jurídicas de la UNAM. México: UNAM. Recuperado de https://archivos. juridicas.unam.mx/www/bjv/libros/7/3219/16.pdf.

Zúñiga, Juan., y González, Susana. (14 de noviembre de 2011). Duplican magnates mineros el oro extraído en la Colonia. La Jornada. Recuperado de http://www. jornada.unam.mx/2011/11/14/min-oro.html.

\section{Fuentes primarias}

Delfina, ejidataria de 33 años, comunicación personal, 20 de mayo de 2016.

Cecilia, habitante de 61 años, comunicación personal, 12 de junio de 2016.

Edith, ejidataria de 75 años, comunicación personal, 24 de mayo de 2016.

Elisa, habitante de 32 años, comunicación personal, 24 de mayo de 2016.

Leonor, ejidataria de 55 años, comunicación personal, 25 de mayo de 2016.

Luisa, ejidataria de 66 años, comunicación personal, 20 de mayo de 2016.

Ofelia, ejidataria de 65 años, comunicación personal, 25 de mayo de 2016. 